\title{
Principles and benefits of the laparoscopic approach in appendicular peritonitis
}

\author{
Carmen-Loredana GORGAN ${ }^{1}$, Florian POPA ${ }^{1}$, Liviu DRAGHICI ${ }^{1,2}$ \\ 1"Carol Davila" University of Medicine and Pharmacy, Bucharest, Romania \\ ${ }^{2}$ General Surgery Department, "Sf. Ioan" Emergency Clinical Hospital, Bucharest, Romania
}

\begin{abstract}
Purpose and objectives. Peritoneal complications of acute appendicitis are inevitable and require a firm attitude both in terms of reducing intraoperative risks but especially in choosing the appropriate therapeutic approach.

Material and method. The paper presents a retrospective biostatistical study of appendicular peritonites operated laparoscopically in the General Surgery Clinic of "Sf. Ioan" Emergency Clinical Hospital of Bucharest between January 2008 and December 2016.

Results. There were 1,275 cases with various forms of acute appendicitis, of which 278 (21.80\%) were complicated forms. Among them, 94 cases $(7.37 \%)$ presented generalized peritonitis with different degrees of severity and $184(14.43 \%)$ cases were localized peritonitis. Generalized peritonitis of appendicular cause was operated laparoscopically in almost $71.27 \%$ of the cases (67 out of 94 generalized peritonitis of appendicular cause). The incidence of postoperative complications was significantly lower in the case of the laparoscopic approach of appendicular peritonitis $(p<0.0001)$, compared to conventional operations.

Conclusions. The indications and limits of the laparoscopic approach in the treatment of appendicular peritonitis are largely dictated by the severity of the lesions, but the experience of the operating team also has an important role.
\end{abstract}

Keywords: minimally invasive approach, appendectomy, complications, lavage, peritoneal drainage, conventional surgery

\section{INTRODUCTION}

After the first laparoscopic appendectomy performed by Kurt Semm [1], laparoscopic appendectomy was among the first minimally invasive procedures widely developed, this intervention being the most common surgical procedure provided by the emergency services. The debate over laparoscopic appendectomy acceptance as preferential approach still exists, although most authors consider today that the laparoscopic approach is the gold standard.

Complicated appendicitis is associated with an increased risk for postoperative complications. After an accurate diagnostic workup including blood sample, ultrasound and/or computed tomodensitometry (CT), an etiologic diagnosis can be established, which may or may not lead to a surgical indication [2]. However, the role of laparoscopy in the complicated appendectomy is not fully settled. Laparoscopic appendectomy has rapidly developed in recent years [3].

The laparoscopic approach for the management of appendicular peritonitis is safe and effective and does not result in any specific complication. Advantages include the high quality of laparoscopic exploration, a very low incidence of septic complications, and a comfortable postoperative recovery [4]. Consequently, 
outcomes of the laparoscopic approach for the management of diffuse appendicular peritonitis (DAP) are poorly documented [5].

\section{MATERIAL AND METHOD}

The article presents the results of a prospective study conducted during 2008-2016, in the General Surgery Clinic of "Sf. Ioan" Emergency Clinical Hospital of Bucharest.

Surgery was performed for various forms of acute appendicitis, some complicated with localized or generalized peritonitis, as immediate,delayed emergency, or scheduled surgery. The surgical teams were led by specialists with considerable experience in laparoscopic techniques, ensuring the premises for adopting the most appropriate solutions for difficult cases and in various challenging intraoperative situations. The positive diagnosis of appendicular peritonitis was based on clinical and imaging examination (ultrasonography and computed tomography) or diagnostic laparoscopy.

In clinical practice, the presence of appendicular peritonitis was not considered in principle a contraindication to the use of the laparoscopic approach.

For the categorical variables (ordinal and nominal) the absolute frequencies (number vs total number = number of occurrences) and relative frequencies expressed in percentages were calculated. The descriptive analysis presents an aspect not to be neglected, namely, the small number of cases from each year studied imposed the consideration of the group as a whole. We used simple and multiple linear regression (if necessary), calculating the odd ratio (OR), coefficients and $95 \%$ confidence intervals $[\mathrm{Cl}]$. The $\chi^{2}$ (chisquare) test was used to compare the categorial data for two or more independent proportions. The test was considered to have statistical significance at a sensitivity level $1-\alpha=0.95$ (the statistical significance threshold was $p \leq 0.05$ ).

All patients (aged $>16$ years) undergoing laparoscopy for appendicular peritonitis (with the presence of purulent fluid with or without fibrin membranes in abdomen) between 2008 and 2016 were retrospectively included. All operations were performed using the three-trocar technique. Three-port method was carried out where a $10 \mathrm{~mm}$ port was inserted at the umbilicus for the $30^{\circ}$ camera, a 5 or $10 \mathrm{~mm}$ port was inserted in the left iliac fossa, and a $5 \mathrm{~mm}$ port was inserted in the suprapubic region. All patients were supine in Trendelenburg's position, tilted to the left. Any adhesions were dissected to expose the appendix and the mesoappendix was secured by electrocautery or LigaSure device. Endoscopic pre-tied loops were used for ligation of the base of the appendix. All areas of the intra-abdominal collection.
Data pertaining to operative time, operative findings, complications, length of hospital admission, and pathological results were reviewed.

\section{RESULTS}

There were 1,275 cases with various forms of acute appendicitis, of which 278 (21.80\%) were complicated forms. Among them, 94 cases (7.37\%) presented generalized peritonitis with different degrees of severity and $184(14.43 \%)$ cases were localized peritonitis and appendicular abscesses (see table 1 ).

In total, 797 (62.53\%) laparoscopic appendectomies and 478 (37.47\%) conventional surgeries were performed (see figure 1). Practically, a double percentage of cases of localized peritonitis (184 cases = $66.18 \%)$ were recorded, compared to that of generalized peritonitis of appendicular cause (94 cases $=$ $33.81 \%$ ) - (see figure 2).

The total number of appendectomies performed annually decreased constantly with the increase of imaging diagnostic performance, but the share of laparoscopic appendectomies increased to $71.42 \%$ of the total of 105 appendectomies performed in 2016 (see table no. 2).

67 cases of generalized appendicular peritonitis were operated laparoscopically, representing $71.27 \%$ of a total of 94 appendicular peritonitis. During that period, each year the number of laparoscopic operations performed for the treatment of appendicular peritonitis exceeded that of open interventions, with one exception, that of 2012, when the cases of appendicular peritonitis were resolved by 7 conventional operations and only 6 laparoscopically (see figure 3).

The laparoscopic accuracy of the diagnosis was $98 \%$. The average duration of laparoscopic operations for appendicular peritonitis was 56 minutes and that of hospitalization was 6 days (see table no. 3). The complication rate was $5.9 \%$ ( 4 out of 67 cases of laparoscopically operated peritonites).

Complicated cases have fully benefited from a minimally invasive approach both in terms of establishing indications for surgery (figure 4 and 5), and in terms of postoperative recovery, while the results of the preoperative clinical evaluation for the severity of peritonitis were corrected by laparoscopic procedure in $11.94 \%$ (8/67 cases).

Compared to classical operations, the minimally invasive approach has proved its advantage in terms of postoperative recovery, the incidence of intraoperative complications being significantly lower in the case of laparoscopic approach to appendicular peritonitis $(p<0.0001)$ (see table 4).

The rate of postoperative morbidity in the laparoscopically operated group was of $7.46 \%$ (5/67 cases), 
TABLE 1. The annual distribution of cases of appendicular and acute appendicitis in the General Surgery Clinic of "Sf. loan" Emergency Clinical Hospital of Bucharest (2008-2016)

\begin{tabular}{|c|c|c|c|c|}
\hline Year & $\begin{array}{c}\text { Appendicular } \\
\text { peritonitis }\end{array}$ & $\begin{array}{c}\text { Appendicular abscesses } \\
\text { with localized peritonitis }\end{array}$ & $\begin{array}{c}\text { Uncomplicated } \\
\text { acute appendicitis }\end{array}$ & $\begin{array}{c}\text { Total forms of } \\
\text { appendicitis }\end{array}$ \\
\hline 2008 & 10 & 19 & 119 & $148(11.61 \%)$ \\
\hline 2009 & 8 & 17 & 113 & $138(10.82 \%)$ \\
\hline 2010 & 11 & 18 & 111 & $140(10.98 \%)$ \\
\hline 2011 & 7 & 19 & 129 & $155(12.15 \%)$ \\
\hline 2012 & 12 & 20 & 134 & $166(13.03 \%)$ \\
\hline 2013 & 13 & 21 & 109 & $143(11.21 \%)$ \\
\hline 2014 & 10 & 23 & 94 & $127(9.96 \%)$ \\
\hline 2015 & 13 & 22 & 99 & $134(10.55 \%)$ \\
\hline 2016 & 10 & 25 & 89 & $124(9.72 \%)$ \\
\hline Total & $94(7.37 \%)$ & $184(14.43 \%)$ & $997(78.20 \%)$ & 1,275 \\
\hline
\end{tabular}

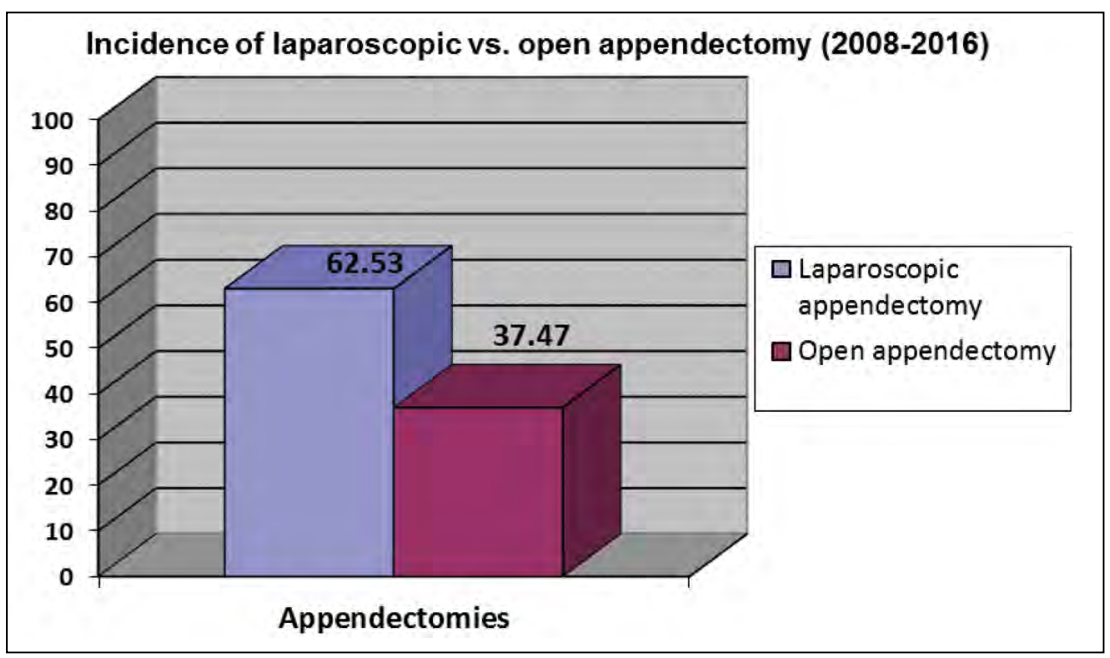

FIGURE 1. Laparoscopic appendectomy vs. conventional appendectomy - the experience of the General Surgery Clinic of "Sf. Ioan"Emergency Clinical Hospital of Bucharest (2008-2016)

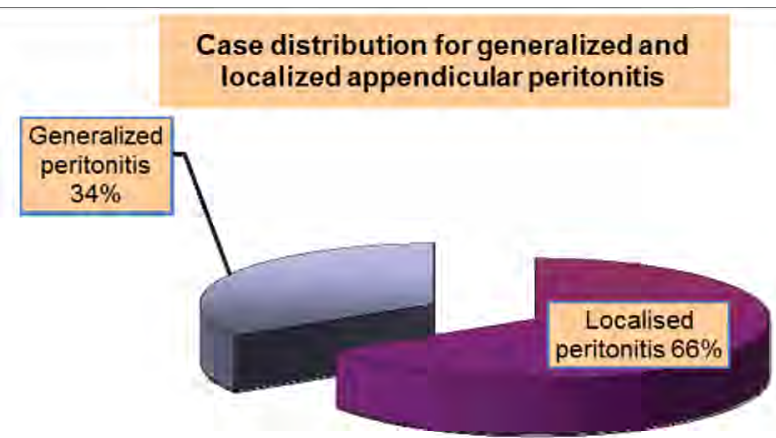

FIGURE 2. Distribution of cases of localized and generalized appendicular peritonitis

TABLE 2. Annual distribution of laparoscopic vs. conventional appendectomies

\begin{tabular}{|c|c|c|c|}
\hline Year & $\begin{array}{c}\text { Appendicular } \\
\text { peritonitis }\end{array}$ & $\begin{array}{c}\text { Classic } \\
\text { appendicitis }\end{array}$ & Total \\
\hline 2008 & 94 & 58 & 152 \\
\hline 2009 & 105 & 38 & 143 \\
\hline 2010 & 98 & 47 & 145 \\
\hline 2011 & 92 & 43 & 135 \\
\hline 2012 & 80 & 65 & 145 \\
\hline 2013 & 89 & 50 & 139 \\
\hline 2014 & 84 & 50 & 134 \\
\hline 2015 & 80 & 49 & 129 \\
\hline 2016 & 75 & 30 & 105 \\
\hline & $797(62.53 \%)$ & $478(37.47 \%)$ & 1,275 \\
\hline
\end{tabular}

the main complications consisting in intraperitoneal abscesses ( 2 cases) (see figure 6$)$, wound infections (1 case) and postoperative hemoperitoneum ( 2 cases). There were no deaths recorded in that group.

\section{DISCUSSION}

The laparoscopic approach of peritonitis is increasingly applied in emergency hospitals, and appendicitis is the main etiological factor. That is why the evaluation of the risks and benefits for the patient must be taken into account in the decision to perform a laparoscopic surgical treatment. Laparoscopic appendectomy has become today the gold standard, enabling a correct and complete diagnosis, reducing trauma parietal and septic complications, and the length of the socio-professional reintegration.

The main advantages offered by the laparoscopic method in the treatment of appendicular peritonitis are provided by accurate and rapid diagnosis, the avoidance of unnecessary median laparotomies, a decreasing need for postoperative analgesics, the reduction of parietal septic complications $[6,7]$ and reduced hospitalization. Moreover, the average length of hospitalization obtained from the mentioned study, in the case of patients with laparoscopic interventions for 


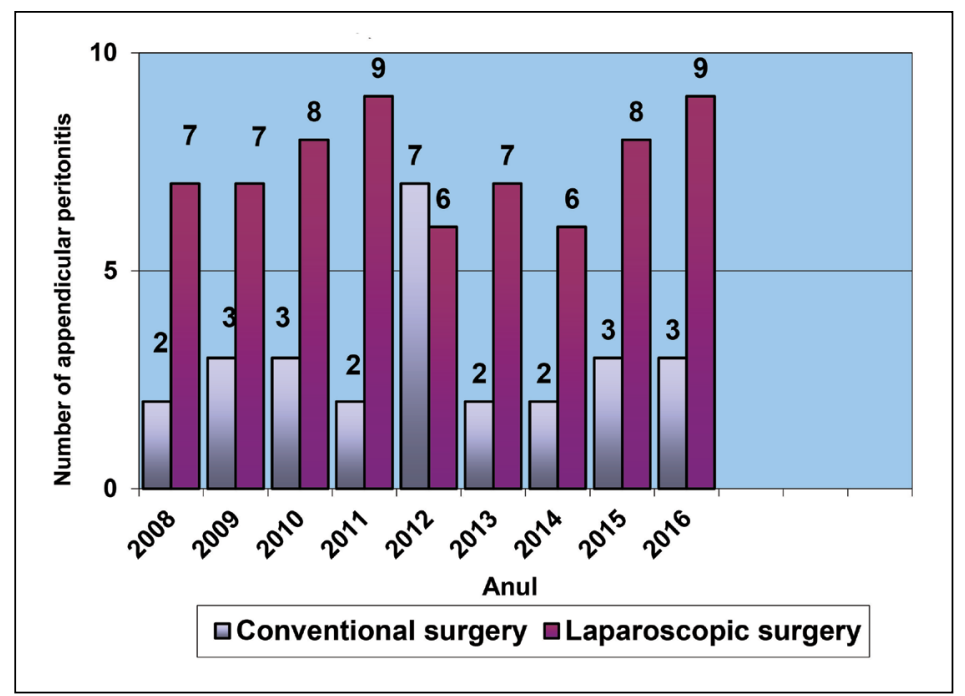

FIGURE 3. Annual distribution of laparoscopic vs. conventional surgeries for appendicular peritonitis (2008-2016)
TABLE 3. Duration of hospitalization for cases with laparoscopic interventions for appendicular peritonitis

\begin{tabular}{|c|c|c|c|}
\hline \multicolumn{4}{|c|}{ Duration of hospitalization (days) } \\
\hline $\mathrm{N}$ & Average & Standard deviation & Median \\
\hline 67 & 6 & 7.22 & 6.74 \\
\hline
\end{tabular}

appendicular peritonitis, was comparable to the average annual length of hospitalization at a national level, in general surgery departments (5.5-6.5 days). Consecrated as a feasible and safe method in the case of appendicular peritonitis, the laparoscopic technique determines the shortening of the convalescence period, the reduction of the global morbidity and the reduction of mortality.

To obtain a maximum therapeutic benefit, it is worth mentioning some particular aspects of the surgical technique and rules to be followed, such as: complete aspiration of the intraperitoneal fluid with the patient in a horizontal position, bacteriological sampling, inspection and dissection of soft and brittle inflamed appendix accompanied by a careful dissection, blunt instruments neighbouring the viscera. At the same time, handling the ceco-appendiceal area must be done carefully because of increased risk of electrical injury (dissection being more cautious with the suction cannula) and extracting the piece to be executed in the bag retainers (figure 7) and the operation will be finalised by carrying out a detailed and abundant repeated lavage with approximately 6-10 liters of warm saline serum, applying the "shaking the patient"technique and later draining with several tubes (figure 8).

It is recommended the neighbouring drainage of appendiceal injury when dissection can be performed safely; in case of breaking, it is necessary to convert the intestinal loops of the performance of open surgery and resection to anastomosis.

Another important aspect worthy of being mentioned is that of the laparoscopic post-appendectomy. There are multiple mechanisms for the production of post-surgery peritonitis, some of them being produced in the peritoneal cavity when accessing, other opera-
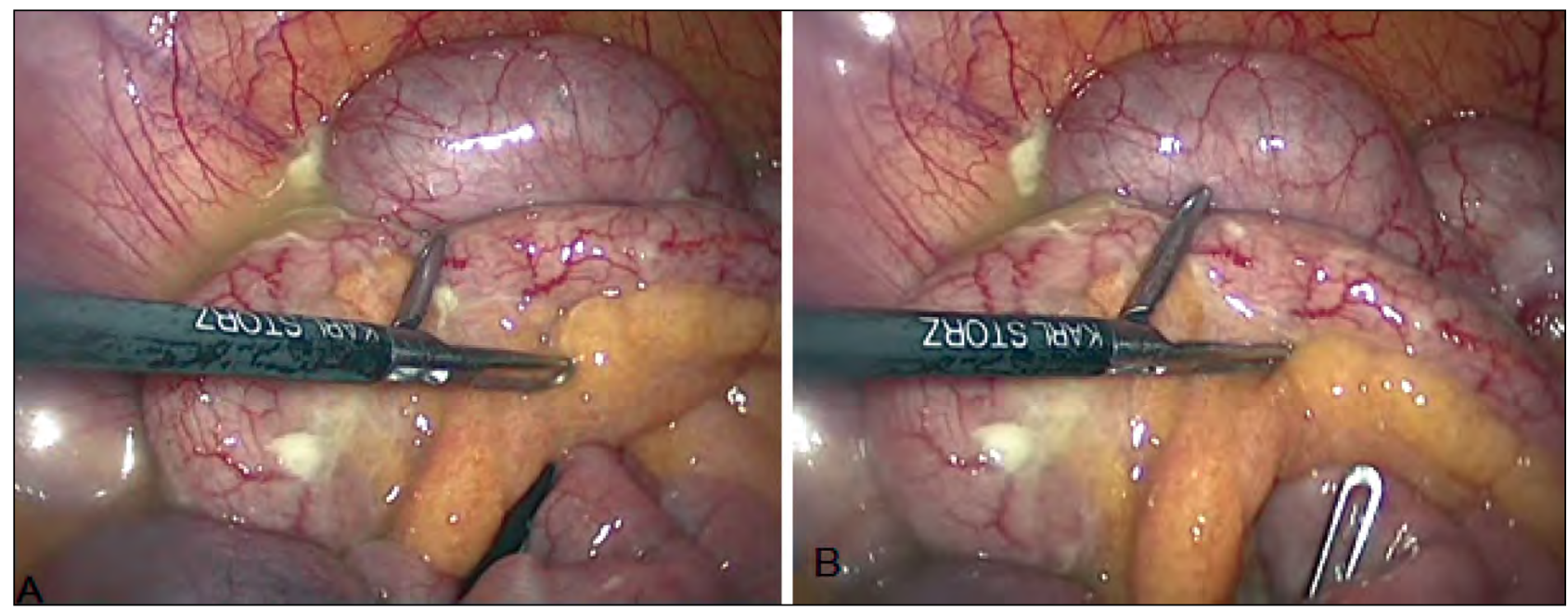

FIGURE 4. Appendicular peritonitis ( $A$ and $B$ ) 


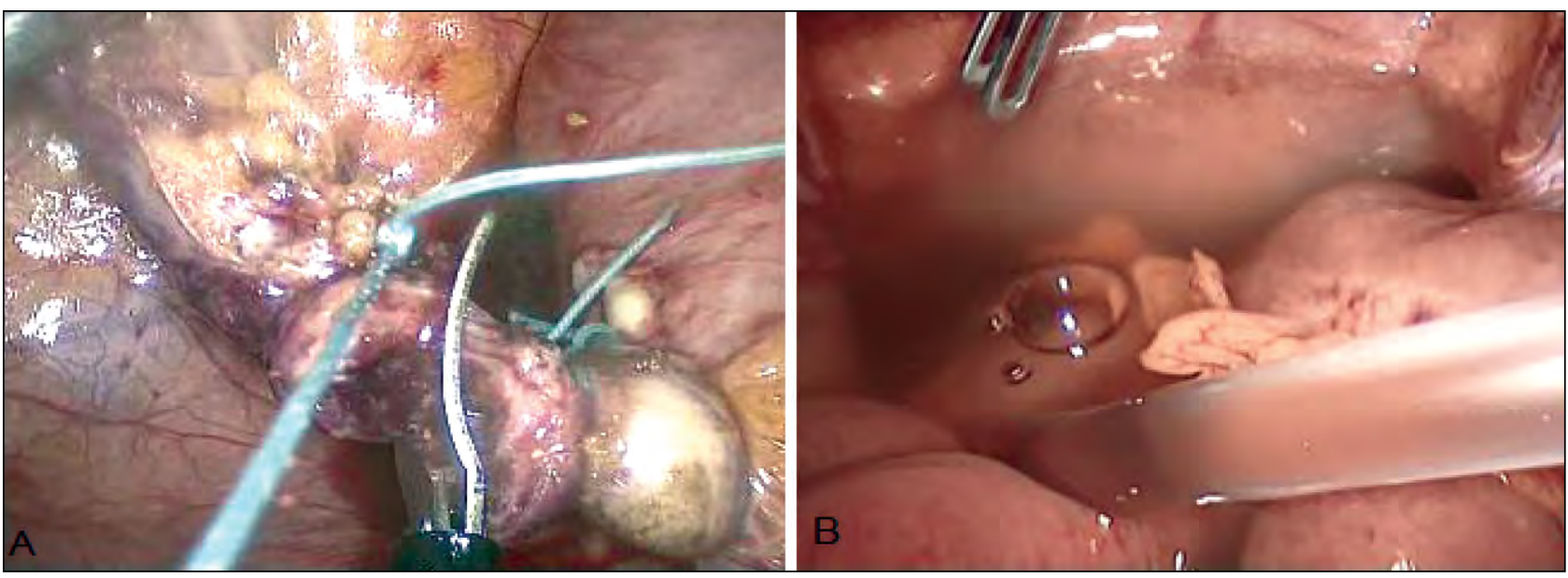

FIGURE 5. Complete laparoscopic management of appendicular peritonitis (appendectomy - $A$, peritoneal lavage and drainage - $B$ )

TABLE 4. The association between postoperative complications and the type of approach for appendicular peritonitis

\begin{tabular}{|l|c|c|c|c|c|c|c|c|}
\hline \multicolumn{2}{|c|}{ The association between postoperative complications and the type of approach (classic / laparoscopic) for appendicular peritonitis } \\
\hline & Absent complications & Present complications & Total & OR & $95 \% \mathrm{Cl}$ & P \\
\hline Surgical approach & $\mathrm{N}$ & $\%$ & $\mathrm{~N}$ & $\%$ & $\mathrm{~N}$ & 0.04 & 0.01 la 0.15 & $<0.0001$ \\
\hline Laparoscopic & 63 & 94.02 & 4 & 5.97 & 67 & & - & \\
\hline Classic & 11 & 40.74 & 16 & 59.25 & 27 & & & \\
\hline
\end{tabular}

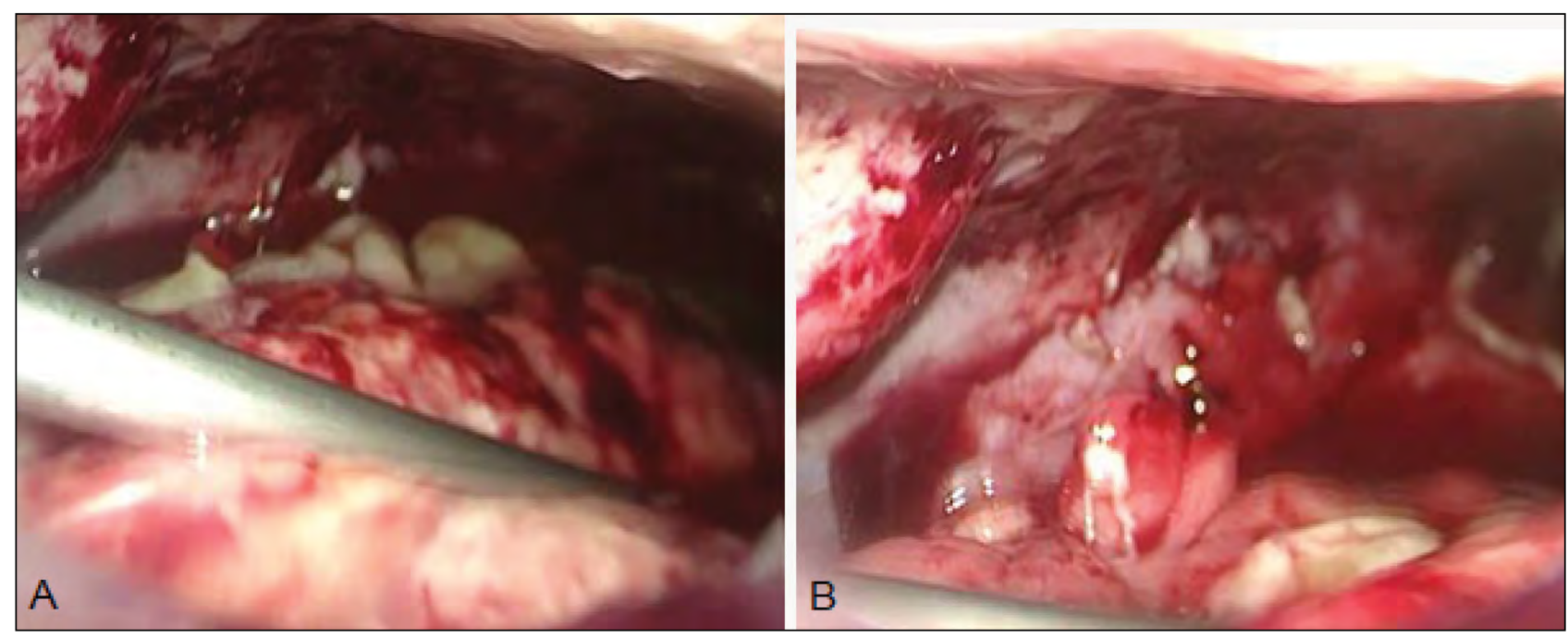

FIGURE 6. Intraperitoneal abscess after laparoscopic appendicectomy (A and B)

tors during the manoeuvres; the amputation stump found as appendix may be caused by excessive ligation or by amputating the appendicular stump, which might be generated by a too tight ligature or by a self-amputation; cecal perforation given the inappropriate handling of the instruments: node pusher, hook or forceps.

Another topic debated in the literature on which various controversies are maintained is related to the fact that pneumoperitoneum would increase bacterial translocation from the peritoneum into the bloodstream [8-13]. There are numerous experimental studies both for and against this hypothesis, but clinical studies recommend the laparoscopic approach [1417].
The problem of performing laparoscopic appendectomy for appendicular peritonitis has also been added to the list of controversies, and Horwitz et al. [18], as well as other authors $[19,20]$, suggested avoiding the laparoscopic approach in complicated appendicitis due to the increased risk of intra-abdominal postoperative abscesses. Laparoscopic treatment of perforated appendicitis is technically more challenging and has been associated to a higher conversion rate than treatment of uncomplicated appendicitis [21-24]. The conversion rates from laparoscopic to conventional appendectomy were estimated between $0 \%$ and $47 \%$, being reported $[7,24-29]$ and correlated with the surgeon's experience [25]. In 2006, specialists in South America published $2.8 \%$ intraperitoneal abscesses af- 


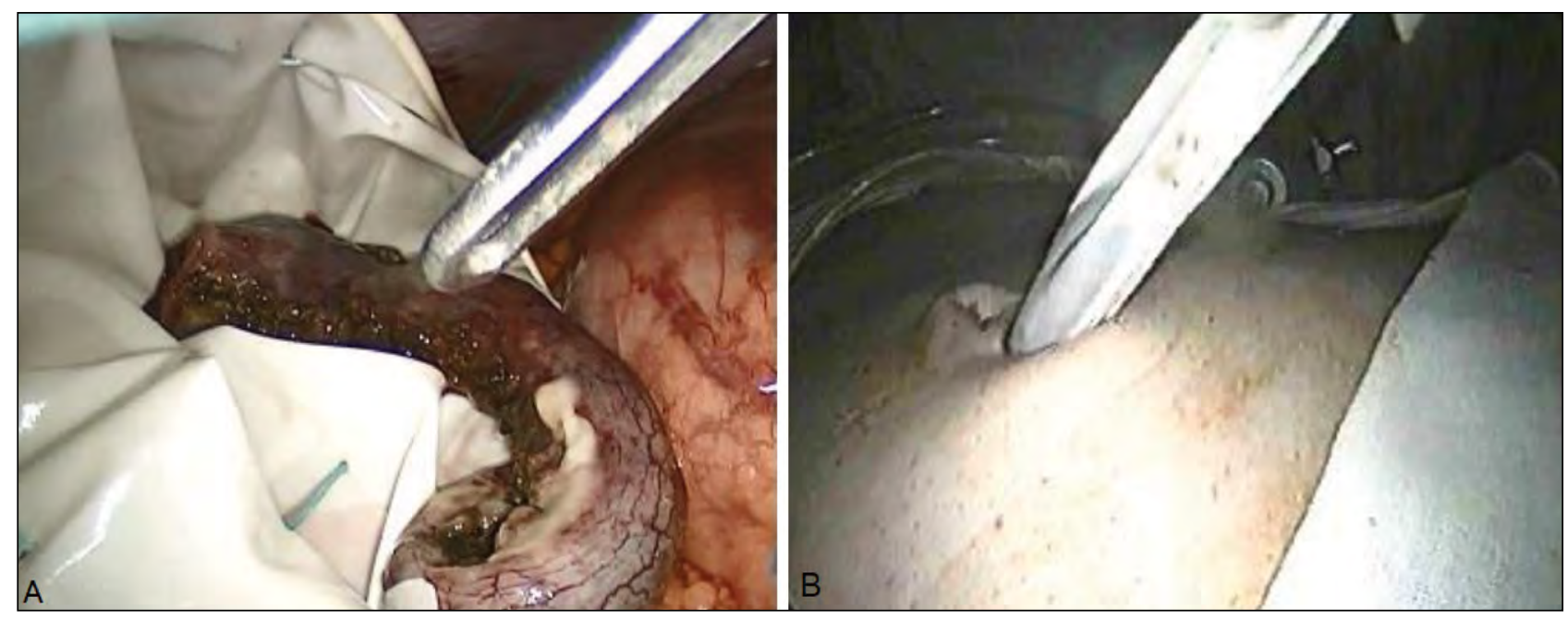

FIGURE 7. Endo-bag extraction (B) of the laparoscopic appendectomy piece ( $A$ and $B$ )

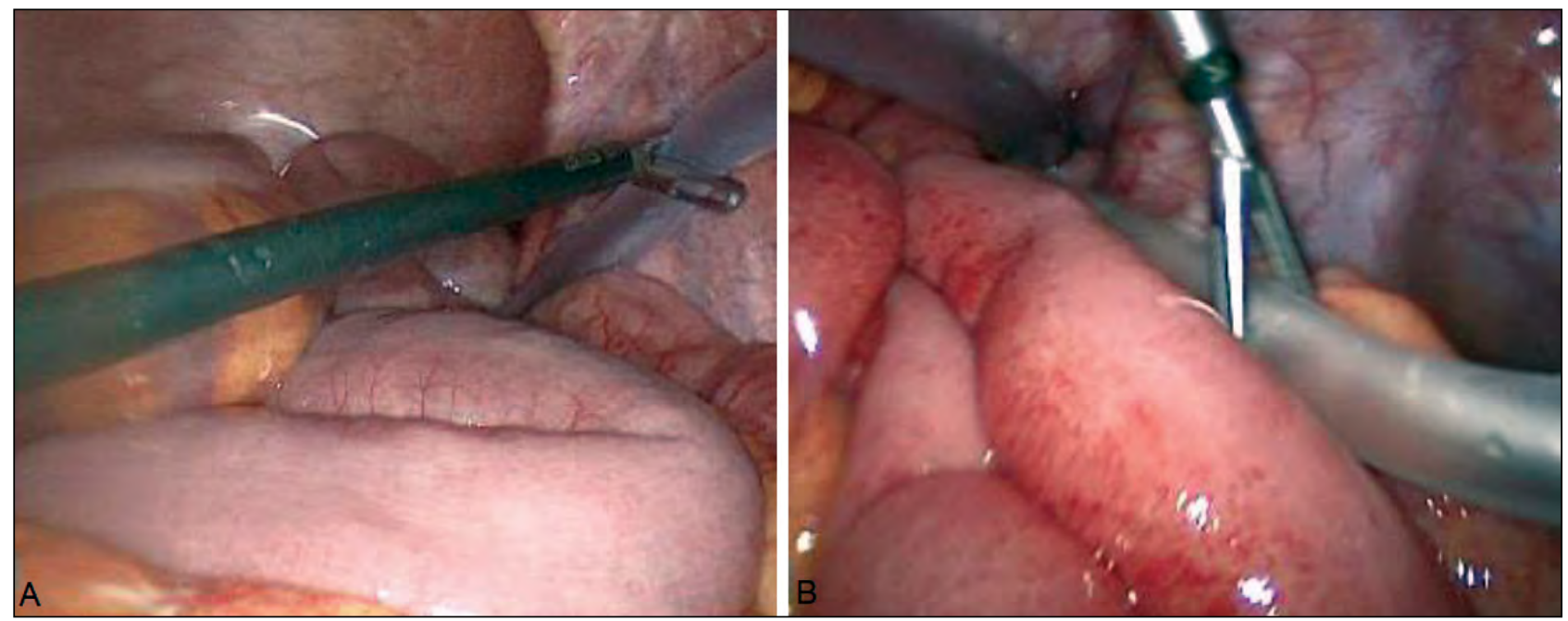

FIGURE 8. Multiple peritoneal lavage and drainage ( $A$ and $B)$

ter laparoscopic appendectomy, in a study conducted on 3,433 cases [30].

Based on extensive experience, we can say that in cases of peritonitis, certain operating times are easy to perform laparoscopically, namely: establishing an accurate diagnosis of the form of appendicitis, performing an effective lavage and adequate drainage of the peritoneum. Likewise, we can say that sometimes it is quite difficult to identify the anatomical landmarks and to dissect the inflamed tissues. From a practical point of view, the most important thing to retain, however, is that not all cases of appendicular peritonitis can be resolved laparoscopically.

\section{CONCLUSIONS}

The laparoscopic appendectomy is the best approach in complicated appendicitis with peritonitis.
The laparoscopic approach of the appendicular peritonitis represents a reproductive and feasible procedure, with acceptable intraoperative incidents and postoperative complications. The method is a recommendable surgical procedure performed in the emergency hospitals in Europe. Indications and limits have to consider the severity of the lesions, the equipment and most of all the laparoscopic experience of the surgical and anaesthetic team.

\section{Acknowledgement}

All the authors are main authors, with equal scientific contributions in the preparation of the article.

Conflict of interest: none declared Financial support: none declared 


\section{REFERENCES}

1. Semm K. Endoscopic appendectomy. Endoscopy 1983;15:59-64.

2. Navez B, Navez J. Laparoscopy in the acute abdomen. Best Pract Res Clin Gastroenterol. 2014;28(1):3-17.

3. Rao BH, Srinivasarao RV. Study of laparoscopic appendicectomy in complicated appendicitis. Int $\mathrm{J}$ Health Sci Res. 2016;6(12):41-46.

4. Navez B, Delgadillo X, Cambier E, Richir C, Guiot P. Laparoscopic approach for acute appendicular peritonitis, efficacy and safety: A report of 96 consecutive cases. Surg Laparosc Endosc Percutan Tech. 2001;11(5):313-6.

5. Thereaux J, Veyrie N, Corigliano N, Servajean S, Czernichow S, Bouillot JL. Is laparoscopy a safe approach for diffuse appendicular peritonitis? Feasibility and determination of risk factors for postoperative intra-abdominal abscess. Surg Endosc. 2014;28(6):1908-13.

6. Piskun G. Comparison of laparoscopic, open and converted appendectomy for perforated appendicitis. Surg Endosc. 2001;15:660-662.

7. Kelly J. The feasibility and accuracy of diagnostic laparoscopy in the septic ICU patient. Surg Endosc. 2000;14:617-621.

8. Evasovich MR. Does pneumoperitoneum during laparoscopy increase bacterial translocation ? Surg Endosc. 1996; 10:1176-9.

9. Ozmen MM. Effect of $\mathrm{CO} 2$ insufflation on bacteremia and bacterial translocation in an animal model of peritonitis. Surg Endosc. 1999;13:801-803.

10. Ipek T. Effect of carbon dioxide pneumoperitoneum on bacteremia and severity of peritonitis in an experimental model. Surg Endosc. 1998;12:432-5.
11. Jacobi CA. Does laparoscopy increase bacteremia and endotoxemia in a peritonitis model? Surg Endosc. 1997;11:235-8.

12. Gurtner GC. Effect of carbon dioxide pneumoperitoneum on bacteraemia and endotoxaemia in an animal model of peritonitis. Br J Surg. 1995;82:844-8.

13. Dugue L, Fritsch S, Felten A, Gossot D, Colomer S, Celerier M, Lagrange P, Revillon Y. Effects of intraperitoneal insufflation on hematogenous seeding of abdominal infections. Preliminary results of an experimental study in rats. Ann Chir. 1995;49:423-6.

14. Orlando R. Laparoscopy in the critically ill. Surg Endosc. 1997;11:1072-1074.

15. Navez B. Laparoscopic management of acute peritonitis. Br J Surg. 2003;85:32-36.

16. Brandt CP. Diagnostic laparoscopy in the intensive care patient. Avoiding the nontherapeutic laparotomy. Surg Endosc. 1993;7(3):168-72.

17. Forde KA. The role of peritoneoscopy (laparoscopy) in the evaluation of the acute abdomen in critically ill patients. Surg Endosc. 1992;6(5):219-21.

18. Horwitz JR, Custer MD, May BH, Mehall JR, Lally KP. Should laparoscopic appendectomy be avoided for complicated appendicitis in children? J Pediatr Surg. 1997;32:1601-3.

19. Paik PS, Towson JA, Anthone GJ, Ortega $A E$, Simons AJ, Beart RW Jr. Intraabdominal abscesses following laparoscopic and open appendectomies. J Gastrointest Surg. 1997;2:188-93.

20. Frazee RC, Bohannon WT. Laparoscopic appendectomy for complicated appendicitis. Arch Surg. 1996;131:509-12.

21. Lin HF, Lai HS, Lai IR. Laparoscopic treatment of perforated appendicitis. World J Gastroenterol. 2014;20(39):14338-47.
22. Johnson AB, Peetz ME. Laparoscopic appendectomy is an acceptable alternative for the treatment of perforated appendicitis. Surg Endosc. 1998;12:940-943.

23. Klingler A, Henle KP, Beller S, Rechner J, Zerz A, Wetscher GJ, Szinicz G. Laparoscopic appendectomy does not change the incidence of postoperative infectious complications. Am J Surg. 1998;175:232-35.

24. So JB, Chiong EC, Chiong E, Cheah WK, Lomanto D, Goh P, Kum CK. Laparoscopic appendectomy for perforated appendicitis. World J Surg. 2002;26:1485-8.

25. Lin HF, Wu JM, Tseng LM, Chen KH, Huang $\mathrm{SH}$, Lai IR. Laparoscopic versus open appendectomy for perforated appendicitis. J Gastrointest Surg. 2006;10:906-10.

26. Fukami Y, Hasegawa H, Sakamoto E, Komatsu S, Hiromatsu T. Value of laparoscopic appendectomy in perforated appendicitis. World J Surg. 2007;31:93-7.

27. Kirshtein B, Bayme M, Domchik S, Mizrahi S, Lantsberg L. Complicated appendicitis: laparoscopic or conventional surgery? World J Surg. 2007;31:744-49.

28. Yau KK, Siu WT, Tang CN, Yang GP, Li MK. Laparoscopic versus open appendectomy for complicated appendicitis. J Am Coll Surg. 2007;205:60-65.

29. Katsuno G, Nagakari K, Yoshikawa S, Sugiyama K, Fukunaga M. Laparoscopic appendectomy for complicated appendicitis: A comparison with open appendectomy. World J Surg. 2009;33:208-214.

30. Cueto J, D'Allemagne B, Vazquez-Frias JA, Gomez S, Delgado F, Trullenque L, Fajardo R, Valencia S, Poggi L, Balli J. Morbidity of laparoscopic surgery for complicated appendicitis: An international study. Surg Endosc. 2006;20(5):717-20. 